\title{
ASSOCIATION BETWEEN PREVENTIVE BEHAVIOUR ON COLORECTAL CANCER AND HEALTH LITERACY AMONG THE ADULT POPULATION IN SARAWAK, MALAYSIA
}

\author{
Drend Jores ${ }^{1}$, Abdul Rahim Abdullah ${ }^{1}$ and Md Mizanur Rahman ${ }^{1}$ \\ ${ }^{1}$ Faculty of Medicine and Health Sciences, Universiti Malaysia Sarawak Sarawak, 94300, Kota Samarahan, Sarawak, \\ Malaysia
}

Corresponding author: Drend Jores

Email: princejowee@gmail.com

\begin{abstract}
Health literacy has shown to have some influence in preventive behaviour, including on colorectal cancer. Such a relationship, however, is not well established in Malaysia, particularly Sarawak. This study is aimed to estimate the level of health literacy and preventive practice against colorectal cancer and factors associated with it. This was a cross-sectional study conducted in Sarawak, among adults aged 50 years and above. Data was collected by face to face interviews using a validated questionnaire. Descriptive statistics were used to determine the health literacy and preventive behaviour on colorectal cancer. Multiple linear regression was used to determine the factors associated with preventive behaviour on colorectal cancer and also to examine its relationship with health literacy. A $p$-value of $\leq 0.05$ was considered as statistically significant. A total of 829 respondents were included in the analysis. Mean age (standard deviation) of the respondents was 55.78 (5.01) years. A large proportion had an educational background of upper secondary school and above (41\%) and from Iban ethnicity (32.4\%). Only $1.1 \%$ of them had a family history of colorectal cancer. Multiple linear regression analysis revealed that gender $(p<0.01)$, ethnicity $(p<0.05)$, functional health literacy $(p<0.05)$, and knowledge on colorectal cancer $(p<0.05)$ appeared to be significant predictors for preventive behaviour on colorectal cancer. Health literacy has a positive effect on preventive behaviour on colorectal cancer. The findings assist in designing and developing targeted informational campaigns to promote preventive behaviour, particularly among low health literate group.
\end{abstract}

Keywords: Preventive behaviour, colorectal cancer, health literacy, Sarawak.

\section{INTRODUCTION}

Colorectal cancer is a multifactorial disease with a set of genetic and environmental factors. The development of colorectal cancer varies, depending on several risk factors. A number of risk factors for colorectal cancer have been identified, mainly related to the lifestyle and behavioural factors such as poor dietary habits, physical inactivity, overweight and obesity, and alcohol consumption ${ }^{1}$. They are not only contributing to a higher risk of colorectal cancer but also had a substantial impact on the health outcomes and quality of life. Apart from that, there are some considerable non-modifiable risk factors such age, gender, ethnicity, family history of colorectal cancer, and inherited genetic risk ${ }^{2}$.

Thus, primary prevention through the adoption of preventive lifestyle remains one of the most effective strategies in reducing the incidence of colorectal cancer and its associated mortality ${ }^{3,4}$. A recent meta-analysis observed a significant reduction in 30-year absolute risk of colorectal cancer among participants with the highest nonmodifiable baseline risk to a level comparable to or below population average risks by changing modifiable risk scores from the highest to the lowest quartile ${ }^{5}$. With regard specifically to colorectal cancer, a local study done found that $18 \%$ of colorectal cancer cases in Malaysia could be prevented by taking appropriate preventive measures such as physically active, having ideal weight and avoiding excessive alcohol consumption ${ }^{6}$. Primary prevention of colorectal cancer thus should be the focus on modifiable risk factors through behavioural modification.

For preventive practices, the individual should have the cognitive skills to access, process and appraise basic health information and services needed to make appropriate health decisions through the concept of health literacy ${ }^{7}$. The earlier concept of health literacy limited to basic literacy skills required for individuals to function adequately within the health care context ${ }^{8}$. However, this does not fully capture the true concept of health literacy. As the new concept evolved, the definition of health literacy moves beyond reading and writing skills which includes the use of social cognition capacities in the comprehension of health information and its application in everyday life. Thus, Nutbeam 9 proposed the three-level of health literacy: functional, interactive and critical health literacy. The first level is functional health literacy which is the sufficient basic skills in reading and writing allowing the individual to understand relevant health information in everyday situations. It emerges as the outcomes of conventional health promotion through the transfer of health knowledge which includes 
health risk and health services utilisation. The second level is communicative health literacy which is the more advanced social cognition skills, enabling the active involvement in the social environment, and to exercise the acquired health knowledge into the changing environment regarding their health. Communicative health literacy emphasises building personal skills to act on the social environment. The third level is critical health literacy with a higher-level cognitive and social skills allowing the individuals to analyse health-related information critically, and to make appropriate health decisions. Individuals with low literacy level may be unlikely to have positive cancer-related health behaviour, such as using preventive services and undergo cancer screening ${ }^{10-13}$. These concepts necessitate for further investigation to gain a better understanding of the linkage between low health literacy and health-related behaviour, especially on colorectal cancer. In addition, such a relationship is not well established in Malaysia, particularly Sarawak.

Sarawak is one of the states in Malaysia, which spreads about 800 kilometres along the northwest coast of Borneo, covering an area of 124,449.51 square kilometres. The population of Sarawak is estimated at 2.87 million ${ }^{14}$ and consists of diverse ethnicity of Iban, Chinese, Malay, Bidayuh, Melanau, Kenyah, Kayan, Penan and many more. Sarawak is divided into three main regions; the southern, central and northern region. The findings from this study would provide an understanding of the relationship between health literacy and health-related behaviour on colorectal cancer among the adult population in Sarawak. It is argued that a low health literacy level could be a higher risk of poor health behaviour and health outcomes. Considering this, the study aimed to examine the relationship between preventive behaviour on colorectal cancer and health literacy and also to determine the predictors of preventive behaviour on colorectal cancer.

\section{METHODS}

This was a cross-sectional study design with quantitative research approach. It was conducted in the southern part of Sarawak from June 2018 to May 2019. To select the study participants', a multistage random sampling technique was adopted. The inclusion criteria include adult population aged 50 years and above. Those with self-history of colorectal cancer and medical or health personnel were excluded from the study. The sample size was determined based on the proportion of respondents of having either poor, moderate or good knowledge and perception regarding colorectal cancer and screening in Peninsular Malaysia ${ }^{15}$. The required sample size was 905 based on the design effect 2, degree of precision at $5 \%$ level and a non-response rate of $20 \%$. A total of 902 respondents participated in this study, a $99.7 \%$ response rate.

\section{Data collection instruments and procedure}

A validated questionnaire was used to collect the data. Depending on respondent preferences, a face-to-face interview was conducted either using the English or the Malay language. The questionnaire was divided into four sections. The first section was designed to determine the respondents' socio-demographic characteristics. The second section was on health literacy assessment, measured by The 14-item Health Literacy Scale (HSL-14) ${ }^{16}$. The third section was designed to assess the level of knowledge regarding colorectal cancer ${ }^{17}$. The last part aims to assess preventive behaviour regarding colorectal cancer ${ }^{18}$. A pilot study was conducted to determine if the research instrument had acceptability, feasibility, and comprehension. Cronbach alphas were used to assess the internal consistency of the items within each domain. The Cronbach alphas were more than 0.7 for all domains except for health-related behaviour domain with Cronbach alphas of 0.612 .

\section{Variables and measurements}

Health literacy: It measures the functional, communicative, and critical aspects of health literacy. A 5-point Likert type rating scale, ranging from zero $(0)$ to four (4) was used. For functional health literacy, a score of four (4) was given for "strongly disagree", three (3) for "disagree", two (2) for "not sure", one (1) for "agree", and zero (0) for "strongly agree". For communicative and critical health literacy, a score of four was given for "strongly agree", three for "agree", two for "not sure", one for "disagree", and zero for "strongly disagree". The scores on the items were summed up for each respondent to give the total health literacy score, as well as functional, communicative, and critical health literacy scores. The maximum score would be 56 , and the minimum score would be zero. Higher scores indicate better health literacy.

Knowledge of colorectal risk: This section consists of 19 items assessing the knowledge regarding risk factors and warning signs of colorectal cancer. All items consist of closedended questions. The items in this section were adopted and modified from the Bowel/Colorectal Cancer Awareness Measure (Bowel/Colorectal CAM) questionnaire ${ }^{17}$. The response was "yes", "no" and "don't know". Each correct answer was given one point while an incorrect answer or "don't know" was given zero points. The total score was summed up to give a total knowledge score. The summative score ranged from zero to 19.

Preventive behaviour against colorectal cancer: Eight item questions were used to assess the diet, physical activity, tobacco smoke, and alcohol consumption. The lifestyle behaviour of diet, physical activity, tobacco smoke and alcohol 
consumption were adopted and modified from the modified checklist used to assess lifestyle behaviours based on FANTASTIC Lifestyle Assessment tool ${ }^{18}$. A score ranged from zero to four was given for each item. A total score was computed to give a total preventive behaviour score. The maximum score would be 32 , and the minimum score would be zero.

Sociodemographic variables: Age, sex, educational background, religion, ethnicity, occupation, marital status, household income, and history of colorectal cancer in self and family members, were considered as independent variables.

\section{Data entry and analysis}

Statistical Package for Social Science (SPSS) version 22 was used to analyse the data19. All the data were being checked thoroughly and cleaned before analysis. Missing data were imputed with multiple imputation procedure ${ }^{20-22}$. A total of 73 cases were removed due to presence of duplication and outliers. A remaining of 829 cases were used as a final data for analysis. Descriptive statistics were used to describe the sociodemographic characteristics and determine the health literacy, knowledge of colorectal cancer and preventive behaviour on colorectal cancer of the respondents. Independent sample ttest and one-way analysis of variance (ANOVA) were applied to determine the differences in means between groups. Multiple linear regression was used to determine the factors associated with preventive behaviour on colorectal cancer and examine its relationship with the health literacy of the respondents. The significant level has stated the p-value of less than 0.05 .

\section{Ethical consideration}

Permission to conduct the study was obtained from local district offices and community leaders. The respondents were briefed about the nature of the study before written informed consent was obtained from each respondent. Confidentiality of information was assured and individual respondent records were treated anonymously. Ethical clearance (reference number: UNIMAS/NC-21.02/03-02 Jld.2(125)) was obtained from the Universiti Malaysia Sarawak (UNIMAS).

\section{RESULTS}

\section{Characteristics of the respondents}

A total of 829 respondents were included in the analysis. Half of the respondents were male (50.5\%). The mean (standard deviation (SD)) age of the respondents was 55.78 (5.01) years. About two-thirds $(41.0 \%)$ of the respondents had an educational background of upper secondary school and above. In term of ethnicity, both Iban and Bidayuh constituted to almost two-thirds of the sample population with $32.4 \%$ and $31.0 \%$, respectively, followed by Chinese (18.5\%) and Malay and other bumiputras (18.0\%). About one- third of the respondents were either housewife or not working (36.1\%), while only $5.5 \%$ were retired. Within the working group, $52.3 \%$ of them were self-employed, $27.3 \%$ worked in the private sector, and $20.4 \%$ of them worked in the public sector. More than $90 \%$ of the respondents were married. Majority of the respondents had a lower income below the mean income of RM1615.37 (SD $=1186.47$ ). Only $2.5 \%$ of the respondents had a family history of colorectal cancer (Table 1).

\section{Health literacy score and knowledge score of the respondents}

Table 2 shows mean score and the level of health literacy, knowledge, health belief and healthrelated behaviour on colorectal cancer among the respondents. Any score below the mean was considered as lower while the score above the mean was categorised as higher. For health literacy, most of the respondents were having lower health literacy with a mean (SD) of 34.18 (8.2). None of the respondents has zero health literacy score with a minimum score of 11 and a maximum score of 56. A further breakdown of health literacy shows that more than $60 \%$ of the respondents had a higher communicative and critical health literacy except for functional health literacy which was almost equivalent for both levels. In term of knowledge, most of the respondents had a higher score with a mean (SD) of 6.83 (4.3). The highest knowledge score was 19 and the lowest score was zero. About $10.4 \%(n=86)$ of the respondents has a score of zero while only $0.1 \%$ of them managed to answer all the items correctly.

Relationship between health literacy, knowledge of colorectal cancer and preventive behaviour with sociodemographic characteristics

Bivariate analysis revealed significant differences in health literacy among different age group $(p<0.001)$, level of education $(p<0.001)$, occupation $(p<0.001)$, marital status $(p<0.001)$ and monthly income $(p<0.001)$. There was no significant difference in health literacy observed among both gender, ethnicity and family history of colorectal cancer $(p>0.05)$. In term of knowledge of colorectal cancer, respondents aged 50 to 59 years, has a higher income and family history of colorectal cancer had a better knowledge compared to their counterparts $(p<0.001)$. Significant differences were also seen among different educational background, ethnicity and occupation $(p<0.001)$. For preventive behaviour, females had a better preventive behaviour score than males $(p<0.001)$. Similarly, those who were married had better preventive behaviour compared to non-married respondents $(p<0.05)$. The analysis also showed a significant difference in preventive behaviour among different ethnicities $(p<0.05)$. There was no significant difference in preventive behaviour 
Table 1: Sociodemographic characteristics

\begin{tabular}{|c|c|c|c|c|c|c|c|}
\hline \multirow[b]{2}{*}{ Characteristics $(n=829)$} & \multirow{2}{*}{$\begin{array}{c}\text { Frequency } \\
\text { (\%) }\end{array}$} & \multicolumn{6}{|c|}{ Mean score (SD) } \\
\hline & & $\begin{array}{l}\text { Health } \\
\text { literacy }\end{array}$ & $\begin{array}{c}\mathrm{p}- \\
\text { value }\end{array}$ & Knowledge & $\begin{array}{c}\mathrm{p}- \\
\text { value }\end{array}$ & $\begin{array}{l}\text { Preventive } \\
\text { behaviour }\end{array}$ & $\begin{array}{c}\mathrm{p}- \\
\text { value }\end{array}$ \\
\hline \multicolumn{8}{|l|}{ Age (years) } \\
\hline $50-59$ & $660(79.6)$ & $35.40(7.8)$ & $<0.001$ & $7.27(4.2)$ & $<0.001$ & $20.21(3.9)$ & 0.059 \\
\hline 60 and above & $169(20.4)$ & $29.39(7.8)$ & & $5.13(4.3)$ & & $20.59(3.6)$ & \\
\hline \multicolumn{8}{|l|}{ Gender } \\
\hline Male & $419(50.5)$ & $34.69(8.0)$ & 0.070 & $7.04(4.2)$ & 0.160 & $20.02(4.0)$ & $<0.001$ \\
\hline Female & 410 (49.5) & $33.66(8.4)$ & & $6.62(4.5)$ & & $22.17(3.6)$ & \\
\hline \multicolumn{8}{|l|}{ Education } \\
\hline No formal schooling & $118(14.2)$ & $26.92(7.0)$ & $<0.001$ & $4.18(4.1)$ & $<0.001$ & $20.66(3.5)$ & 0.551 \\
\hline Primary & $199(24.0)$ & $32.07(8.0)$ & & 4.99 (3.5) & & $21.01(3.8)$ & \\
\hline Lower secondary & $172(20.7)$ & $33.56(6.9)$ & & 6.89 (3.9) & & $21.23(3.8)$ & \\
\hline Upper secondary \& above & $340(41.0)$ & $38.24(6.8)$ & & $8.81(4.0)$ & & $21.21(3.9)$ & \\
\hline \multicolumn{8}{|l|}{ Ethnicity } \\
\hline Iban & $269(32.5)$ & $34.36(9.2)$ & 0.301 & $6.14(4.4)$ & $<0.001$ & $20.66(3.8)$ & $<0.05$ \\
\hline Bidayuh & $257(31.0)$ & $33.99(7.6)$ & & $5.72(4.3)$ & & $20.68(4.1)$ & \\
\hline Chinese & $153(18.5)$ & $33.32(7.3)$ & & $7.82(3.3)$ & & $21.67(3.0)$ & \\
\hline Malay \& others bumi & $150(18.0)$ & $35.05(8.2)$ & & $8.99(4.1)$ & & $21.94(3.8)$ & \\
\hline \multicolumn{8}{|l|}{ Occupation } \\
\hline Public sector & 99 (11.9) & $39.75(6.5)$ & $<0.001$ & $9.34(3.8)$ & $<0.001$ & $21.04(3.8)$ & 0.05 \\
\hline Private sector & $132(15.9)$ & $36.54(7.4)$ & & $7.21(3.9)$ & & $20.48(4.0)$ & \\
\hline Self-employed & $253(30.5)$ & $33.24(7.6)$ & & $6.54(4.2)$ & & 20.64 (3.9) & \\
\hline Housewife/unemployed & $299(36.1)$ & $31.84(8.5)$ & & $5.91(4.3)$ & & $21.71(3.6)$ & \\
\hline Retired & $46(5.5)$ & $35.80(7.1)$ & & $7.98(5.1)$ & & $21.33(3.9)$ & \\
\hline \multicolumn{8}{|l|}{ Marital status } \\
\hline Married & 776 (93.6) & $34.45(8.1)$ & $<0.001$ & $6.92(4.3)$ & $<0.05$ & $21.12(3.8)$ & $<0.05$ \\
\hline Non-married & $53(6.4)$ & $30.17(8.5)$ & & $5.58(4.5)$ & & $20.57(4.0)$ & \\
\hline \multicolumn{8}{|l|}{ Monthly income (RM)* } \\
\hline Lower & 513 (61.9) & $32.44(8.5)$ & $<0.001$ & $5.71(4.3)$ & $<0.001$ & $21.08(4.0)$ & 0.925 \\
\hline Higher & $316(38.1)$ & $37.00(6.8)$ & & $8.66(3.7)$ & & $21.10(3.6)$ & \\
\hline \multicolumn{8}{|l|}{$\begin{array}{l}\text { Family history of } \\
\text { colorectal cancer }\end{array}$} \\
\hline No & 808 (97.5) & $34.10(8.2)$ & 0.078 & $6.75(4.3)$ & $<0.001$ & 21.07 (3.8) & 0.411 \\
\hline Yes & $21(2.5)$ & $37.29(7.3)$ & & $10.29(4.0)$ & & $21.76(4.5)$ & \\
\hline
\end{tabular}

$a: p$-value from the independent $t$-test, $b: p$-value from one way ANOVA

*Lower income= below the mean; higher income= above the mean

Table 2: Health literacy score and knowledge score of the respondents

\begin{tabular}{lcr}
\hline Domain & Frequency, $\mathbf{n}(\%)$ & Mean (SD) \\
\hline Health literacy & $444(53.6)$ & $34.18(8.2)$ \\
Lower & $385(46.4)$ & \\
Higher & & $9.84(5.2)$ \\
Functional health literacy & $409(49.3)$ & \\
Lower & $420(50.7)$ & $12.93(3.2)$ \\
Higher & & \\
Communicative health literacy & $323(39.0)$ & \\
Lower & $506(61.0)$ & \\
Higher & & \\
Critical health literacy & $299(36.1)$ & \\
Lower & $530(63.9)$ & \\
Higher & & \\
Knowledge & $391(4.2)$ \\
Lower & $438(52.8)$ \\
Higher & & \\
\hline
\end{tabular}


observed among different age groups, education status, occupation, monthly income and family history of colorectal cancer $(p>0.05)$.

\section{Factors associated with preventive behaviour against colorectal cancer: Multiple linear regression}

A standard multiple linear regression analysis was done to determine the factors predicting preventive behaviour on colorectal cancer. Categorical variables were coded as 0 and 1. For gender, the male was coded as 0 while female as 1. For ethnicity, Chinese and Malay \& others Bumi were categorised as non-Dayak while Iban and Bidayuh were categorised as Dayak. Subsequently, non-Dayak were coded as 0 while Dayak as 1. For marital status, 0 was coded for married while 1 was coded for non-married. Exploratory data analysis was done to check for any multicollinearity, normality and outliers ${ }^{22}$. A total of 778 cases were used as final data for analysis.

Using the enter method, the final model was statistically significant, $F(4,777)=30.91 ; p<0.001$ and explain the total variance of $13.8 \%$ of preventive behaviour. Gender, ethnicity, functional health literacy and knowledge on colorectal cancer were the significant predictors of preventive behaviour among the respondents. Gender has the highest $B$ value $(B=0.316$, $p<0.001)$, followed by ethnicity $(B=-0.130$, $p<0.05)$ and knowledge on colorectal cancer $(B=0.105, p<0.05)$. Functional health literacy has the weakest contribution towards preventive behaviour of colorectal cancer $(B=0.083, p<0.05)$. This shows that females were more likely to have better preventive behaviour compared to males. Besides, those with better knowledge, better functional health literacy and from non-Dayak ethnicity were more likely to engage in preventive behaviour on colorectal cancer (Table 3).

\section{DISCUSSION}

This study demonstrated a significant relationship between functional health literacy and preventive behaviour against colorectal cancer. Individuals with lower health literacy tended to have poor preventive actions and exposed them to the development of the disease such as cancer. Several studies have shown a similar pattern, although the tools used to measure the health literacy were differed ${ }^{11,23-25 .}$. Functional health literacy is one of the components in health literacy apart from communicative and critical health literacy. It is a basic skill that is needed to read and write, allowing the individual to understand relevant health information in everyday situations. The finding in this study could signify that health literacy itself at a very first level has an important role in improving health behaviour among the population, particularly with regards to colorectal cancer behaviour.

Among the other important predictors for preventive behaviour includes gender, ethnicity, and knowledge of colorectal cancer. Females were more likely to engage in preventive behaviour on colorectal cancer compared to males. The differences in gender have been reported across a range of health-related behaviours, including health seeking behaviours and disease prevention strategies ${ }^{26,27}$. The fact is that females tend to have a non-fatal illness with a longer life expectancy while male suffer more life-threatening chronic diseases with shorter life expectancy ${ }^{28}$. This could probably motivate the female to engage more in preventive health behaviour, including cancer. Ethnicity appeared to have some substantial influence on preventive behaviour. This study shows that those from the non-Dayak group were more likely to engage in preventive behaviour on colorectal cancer. Nonetheless, a local study done found no significant difference in healthy lifestyle practice among various ethnicity ${ }^{29}$. Differences in the category used to classify the ethnic group could explain the discrepancy.

Knowledge of colorectal cancer appeared to be another predictor for preventive behaviour. An individual with better knowledge of colorectal cancer tends to have better preventive behaviour on colorectal cancer and is consistent with previous studies ${ }^{30-32}$. The effect of knowledge could be translated, that leads to behavioural changes or motivation to perform the behaviour of an individual. Thus, it could be the primary area for disease intervention to promote healthy behaviour such as physical activity and participation in cancer screening.

Table 3: Factors predicting preventive behaviour against colorectal cancer

\begin{tabular}{lcccc}
\hline \multicolumn{1}{c}{ Variable } & $\begin{array}{c}\text { Std. B } \\
\text { coefficient }\end{array}$ & $95 \% \mathrm{Cl}$ & $\mathrm{t}$ & $\mathrm{p}$-value \\
\hline Gender & $0.316^{* *}$ & $1.636,2.496$ & 9.427 & 0.001 \\
Ethnicity & $-0.130^{*}$ & $-1.337,-0.413$ & -3.715 & 0.020 \\
Functional health literacy & $0.083^{*}$ & $0.009,0.098$ & 2.338 & 0.044 \\
Knowledge on colorectal cancer & $0.105^{*}$ & $0.025,0.137$ & 3.848 & 0.018 \\
\hline
\end{tabular}

$\mathrm{F}(4,777)=30.91, \mathrm{p}<0.001$

$\mathrm{R}^{2}=0.138$

${ }^{*}<0.05,{ }^{* *}<0.01$ 
This study has some potential limitation. The use of cross-sectional design only able to establish an association and does not establish causality. Another limitation was concerning the use of selfreported measures of behaviour. Self-reporting are often associated with recall bias. Despite this limitation, the use of self-reported measures is still the most preferred method in collecting the information from the respondents and became a method of choice in this study.

\section{CONCLUSION}

Health literacy could have some effect on preventive behaviour on colorectal cancer. Besides, gender, monthly income and knowledge appear to have some contribution in predicting preventive behaviours. Understanding the factors associated with low preventive behaviours provide the basis for the development of successful interventions. The population group with low literacy level, which indicate a higher risk of having poor health behaviour and health outcomes can be identified, thus assist in designing and developing targeted informational campaigns for this low health literate group.

\section{ACKNOWLEDGEMENT}

We would like to acknowledge all the respondents for their willingness to participate in this study. We also would like to thanks the respective district officers and community leaders for their generous cooperation in this study. Special thanks to the Department of Community Medicine and Public Health, Universiti Malaysia Sarawak (UNIMAS) for their support in making this study to be successful.

\section{FUNDING}

\section{Self-funded}

\section{CONFLICT OF INTEREST}

The authors declare the absence of conflicting interests.

\section{AUTHORS' CONTRIBUTION}

DJ was involved in concept design, data collection, analysis and drafted the manuscript. ARA helped in conceptualizing the research design, supervised the study process, edited the draft manuscript. MMR involved in research design, sampling, analysis and interpretation of results and drafted the manuscript. All authors read and approved the final manuscript.

\section{REFERENCES}

1. World Cancer Research Fund International/American Institute for Cancer Research. Continuous Update Project Expert Report. Diet, nutrition, physical activity and colorectal cancer; $2018 . \quad 109 \quad$ p. www.wcrf.org/sites/default/files/Colore ctal-cancer-report.pdf (accessed 28 December 2020).

2. Wing $M C$, Ding $\mathrm{H}$, Wang $\mathrm{J}$, et al. Prevalence and risk factors of colorectal cancer in Asia. Intestinal Research 2019; 17(3): 317-319.

3. Lopez PJT, Albero JS, Rodriguez-Montes JA. Primary and secondary prevention of colorectal cancer. Clinical Medicine Insight: Gastroenterology 2014; 7:33-46.

4. Torre LA, Siegel RL, Ward EM, Jemal A. Global cancer incidence and mortality rates and trends: An update. Cancer Epidemiology Biomarkers \& Prevention 2016; 25(1):16-27.

5. Wang $\mathrm{X}$, O'Connell $\mathrm{K}$, Jeon $\mathrm{J}$, et al. Combined effect of modifiable and nonmodifiable risk factors for colorectal cancer risk in a pooled analysis of 11 population-based studies. BMJ Open Gastroenterology 2019; 6(1): e000339.

6. Naing C, Lai PK, Mak JW. Immediately modifiable risk factors attributable to colorectal cancer in Malaysia. BMC Public Health 2017; 17(637).

7. Batterham RW, Hawkins M, Collins PA, et al. Health literacy: applying current concepts to improve health services and reduce health inequalities. Public Health 2016; 132: 3-12.

8. Rudd RE. Health literacy: Insights and issues. In: Logan RA, Siegel ER, eds. Health Literacy: New directions in research, theory and practice. Amsterdam: IOS Press 2017: 60-64.

9. Nutbeam D. Health literacy as a public health goal: a challenge for contemporary health education and communication strategies into the 21st century. Health Promotion International 2000; 15(3); 259-267.

10. Davey J, Holden CA, Smith BJ. The correlates of chronic disease-related health literacy and its components among men: A systematic review. BMC Public Health 2015; 15:589.

11. Fernandez DM, Larson JL, Zikmund-fisher BJ. Associations between health literacy and preventive health behaviors among older adults: Findings from the health and retirement study. BMC Public Health 2016; 16(596). 
12. Kim K, Han H, Koay K., Potential links between health literacy and cervical cancer screening behaviors: a systematic review. Psycho-Oncology 2016; 25(2):122-130.

13. Sentell TL, Tsoh JY, Davis T, et al. Low health literacy and cancer screening among Chinese Americans in California: a cross-sectional analysis. BMJ Open 2015; 5: e006104.

14. Economic Planning Unit Sarawak. Sarawak Facts and Figures 2019. Sarawak: Chief Minister's Department; 2019: 68 p. www.jkm.sarawak.gov.my/SPU/page-00-346-.html (accessed 30 December 2020).

15. Hilmi I, Hartono JL, Goh KL. Negative perception in those at highest risk Potential challenges in colorectal cancer screening in an urban Asian population. Asian Pasific Journal of Cancer Prevention 2010; 11:815-22.

16. Suka M, Odajima T, Kasai M, et al. The 14item health literacy scale for Japanese adults (HLS-14). Environ Health Prev Med 2013; 18:407-15.

17. Power E, Simon A, Juszczyk D, et al. Assessing awareness of colorectal cancer symptoms: Measure development and results from a population survey in the UK. BMC Cancer 2011; 11(366).

18. Dennis DL, Waring JL, Payeur N, Cosby C. Making lifestyle changes after colorectal cancer: Insights for program development. Current Oncology 2013; 20(6): e493-511.

19. IBM SPSS. IBM SPSS Statistics for Windows (Version 22) 2013. [Computer software].

20. Garson GD. Missing values analysis and data imputation (second). Statistical Associates Publishers 2015. http://www.statisticalassociates.com/m issingvaluesanalysis.htm (accessed 2 November 2020).

21. Jakobsen JC, Gluud C, Wetterslev J, et al. When and how should multiple imputation be used for handling missing data in randomised clinical trials - a practical guide with flowcharts. BMC Medical Research Methodology 2017; 17(1):162.

22. Sharma A. Understanding Mahalanobis distance and its use cases. Analytics India Magazine 2018, July 10. https: / / www.analyticsindiamag.com/un derstanding-mahalanobis-distance-andits-use-cases/ (accessed 2 November 2020).

23. Garcia-Codina O, Juvinyà-Canal D, AmilBujan P, et al. Determinants of health literacy in the general population: Results of the Catalan health survey. BMC Public Health 2019; 19:1122.

24. Kobayashi LC, Wardle J, Wolf MS, et al. Health literacy and moderate to vigorous physical activity during aging , 2004-2013. American Journal of Preventive Medicine 2016; 51(4):463-472.

25. Reisi M, Javadzade SH, Heydarabadi AB, et al. The relationship between functional health literacy and health promoting behaviors among older adults. Journal of Education and Health Promotion 2014; 3:119.

26. Thompson AE, Anisimowicz Y, Miedema B, et al. The influence of gender and other patient characteristics on health careseeking behaviour: a QUALICOPC study BMC Family Practice 2016; 17: 38

27. Hiller J, Schatz K, Drexler H. Gender influence on health and risk behavior in primary prevention: A systematic review. Journal of Public Health 2017, 25(4): 339349.

28. Crimmins EM, Shum H, Zhang YS, et al. Differences between men and women in mortality and the health dimension of the morbidity process. Clinical Chemistry 2019; 65(1): 135-145.

29. Froze S, Arif MT, Saimon R. Determinants of health literacy and healthy lifestyle against Metabolic Syndrome among major ethnic groups of Sarawak, Malaysia: A multi-group path analysis. The Open Public Health Journal 2019; 12:172-83.

30. Taheri-Kharameh Z, Noorizadeh F, Sangy $\mathrm{S}$, et al. Factors associated with $\mathrm{Ng}$ EST, Tan adherence to colorectal cancer screening among moderate risk individuals in Iran. Asian Pacific Journal of Cancer Prevention 2016; 16(18): 83718375.

31. Wutayd OA, Alamri F, Ali AM, et al. Colorectal cancer risk factors: a study of knowledge, attitude and practice among adults in Riyadh, Saudi Arabia. Cancer Research Journal 2015; 3(5): 94-99.

32. Sharbatti S Al, Muttappallymyalil J, Sreedharan J, et al. Knowledge, perception, and preventive practices 
regarding colorectal cancer among adults in Ajman, UAE. Gulf Medical Journal 2014; 3:35-49. 